\title{
The Inversion Method of Industrial Flame Vertical Temperature Field Based on Multi-spectral Radiation
}

\author{
Zhenhua Wei ${ }^{1}$, ${ }^{*}$ Binyang $\mathrm{Li}^{1}$, Zhihong $\mathrm{Li}^{1}$, Shibo Song ${ }^{2}$ and $\mathrm{Yan}_{\mathrm{Li}^{1}}$ \\ ${ }^{1}$ School of Control and Computer Engineering, North China Electric Power \\ University Beijing 102206 \\ ${ }^{2}$ Math and Science Department, Harbin University, Harbin 150080
}

\begin{abstract}
It is important to supervise the combustion conditions of large coal-fired boiler to ensure the safety of boiler, which will benefit our economy and environment. Now, the traditional devices such as thermocouple and industrial television are used when monitoring combustion condition. Because of the internal defects of these devices and the complexity of flame in the industry boiler, the current method cannot satisfy the needs of safe operation. Here, we proposed an inversion method for the industrial flame vertical temperature field based on multi-spectral radiation. In order to improve the calculation speed of the method, the particle swarm optimization technique was applied to control the convergence process. Experiments were performed, showing that the proposed method for the inverse vertical industrial flame temperature field is feasible and has higher accuracy. Compared with current industrial flame field temperature measurement methods, the proposed method in this manuscript has the advantages of simple operation, high precision, and fast convergence speed.
\end{abstract}

Keywords: Industrial flame; Multi-spectral radiation; Vertical Temperature Field inversion; Particle swarm optimization

\section{Introduction}

With the rapid development of industry in the world, a great number of large boilers are continuously put into production. The basic requirement for boiler combustion stability is to maintain stable combustion flame. In actual industrial production, Uneven in the boiler combustion flame and deflection of the flame, leading to some serious safety and operation problems such as furnace slagging, furnace tube blasting and environmental pollution, etc. Therefore, to guarantee the safe operation of the boiler and increase the combustion efficiency and save energy, it is important to know the flame combustion conditions and monitor the temperature field in furnace accurately and effectively.

In the past, furnace combustion flame's temperature and distribution has mostly been measured by thermocouple. The contacting temperature measurement method is flawed with narrow temperature range, short service life, slow response, large error, etc. [1-3] Due to non-contact temperature measurement method avoid these disadvantages [4], there are many reports in flame temperature measurement based on it. Docquier $\mathrm{N}$ and Candel $S$ reviewed the sensors and facets used for combustion control solution [5]. Huaichun Zhou and others proposed a method to calculate the two dimensional temperature field distributions from the flame radiation energy with the aid of radiation and reference point, adopting point two-color method to calibrate the measuring thermometer [6]. Dong Liu solved the inverse problem of radiation in $2 \mathrm{~d}$ and $3 \mathrm{~d}$ medium, and tried to adopt the backward and forward Monte Carlo method to inverse the temperature field in the coalfired boiler [7-8]. A theory was developed by Khan to predict the errors in the estimation of temperatures based on both linear and nonlinear least-squares techniques [9]. Yuefeng $\mathrm{Yu}$ and others used images to obtain flame information for the flame detection [10]. 
However, these methods are difficult to be applied to industrial flame temperature field measurement. Due to the large range and continuous pulse of the combustion flame in the furnace chamber, the temperature is distributed as a three dimensional field. To monitor its behavior, traditional single-point measurement method cannot satisfy the requirement. However, effective three-dimensional visual monitoring system for the hearth hasn't been established, and it is difficult to inspect the reconstruction results of the furnace flame temperature field. So far, the main method used is to do numerical simulation by computer. Therefore, a new effective temperature field distribution measurement system has important research significance and practical value.

In the present study, we proposed a flame temperature measurement method based on the principle of the multispectral radiation. This method has the following advantages: non-contact, wide temperature range, fast measuring speed, and long service life. On the basis of the temperature measurement, the particle swarm optimization technique is applied to the control of industrial flame temperature longitudinal inversion convergence to improve the speed of flame longitudinal temperature calculation. To confirm the feasibility of this method, a series of simulation experiments and analysis have been performed. Our results show that the flame temperature field measurement method proposed here is feasible.

\section{Experiment Facilities}

The temperature measurement system used in experiment consists of optical platform, speculum group, spectral apparatus, color filter, photosensitive diode, acquisition board and computer (Figure 1).

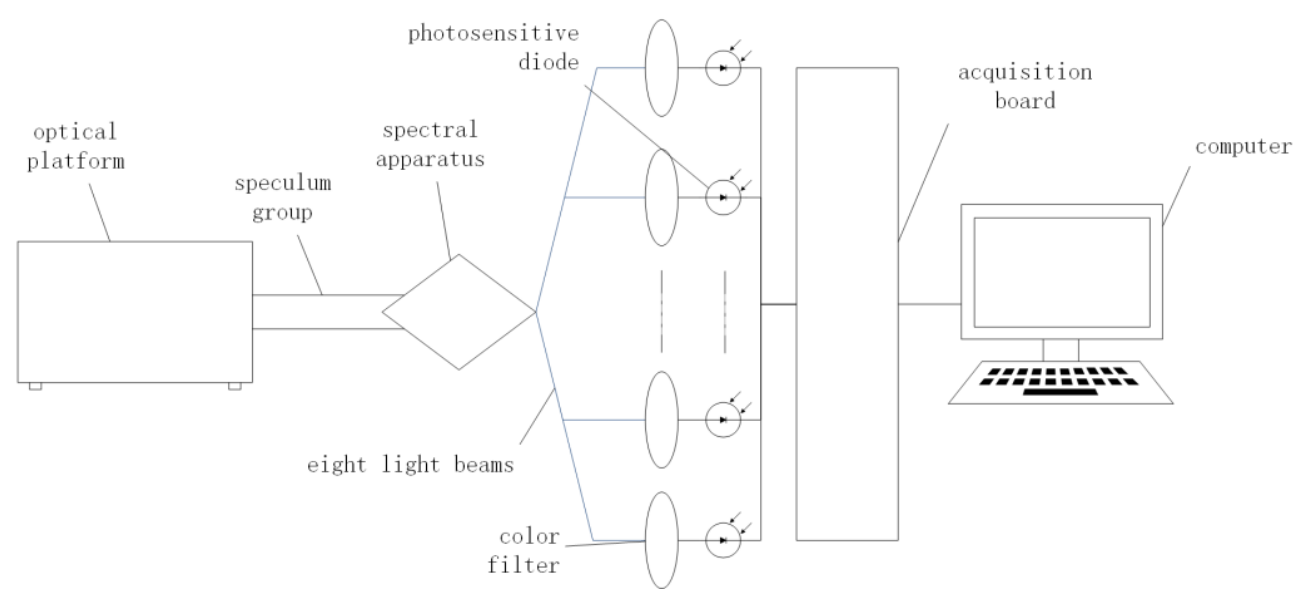

Figure 1. Temperature Measurement System

In the system, optical platform acquires industrial furnace flame radiation signal. Its position is adjusted until the system obtains the largest light signal strength. After passing through spectral apparatus, flame light will be divided into eight beams. Then using color filters of different wavelength, eight different wavelengths of light (wavelength range is $450 \mathrm{~nm}-800 \mathrm{~nm}$ ) can be obtained. The wide range of the d is $400 \mathrm{~nm}$ to $900 \mathrm{~nm}$, which converts light signals into voltage signal. Acquisition board will receive these data and then send them to the computer. Finally, using the computer for data analysis and processing, the flame temperature and vertical temperature field will be calculated. 


\section{Measurement Principal}

\subsection{Thermal Radiation Law}

Any objects with temperature above absolute zero emit radiation. Blackbody is the most ideal thermal radiator, because it fully absorbs any energy that radiate to its surface without rebounding and transmission. It can emit the maximum thermal radiation to a certain temperature. Planck law describes this kind of ideal radiation phenomenon:

$$
E_{b}(\lambda, T)=\frac{C_{1}}{\lambda^{5}\left[\exp \left(\frac{C_{2}}{\lambda T}\right)-1\right]}
$$

Where $E_{b}(\lambda, T)$ presents the unit wavelength of spectral radiation intensity from a radiation graphic to the hemisphere with the wavelength $\lambda$. Unit is $\mathrm{W} /\left(\mathrm{m}^{2} \cdot \mu \mathrm{m}\right)$.

$\mathrm{C}_{1}$ is the first Planck radiation constant, $\mathrm{C}_{1}=3.743 * 108 \mathrm{~W} \cdot \mu \mathrm{m}^{2}$.

$\mathrm{C}_{2}$ is the second Planck radiation constant, $\mathrm{C}_{2}=1.439 * 104 \mu \mathrm{m} \cdot \mathrm{K}$.

$\lambda$ is wavelength ( $(\mathrm{HrI})$, and $T$ is black body's absolute temperature $(\mathrm{K})$.

Blackbody radiation is a continuous spectrum. Theoretically, as long as the radiation intensity of a certain wavelength can be measured, Blackbody's absolute temperature can be calculated according to formula (1).

\subsection{Temperature Measurement Method}

According to Planck Law, a mathematical model of flame temperature measurement can be obtained. In the temperature measurement system, the flame light is divided into eight beams. $\mathrm{V}_{\mathrm{i}}$ is the ith light beam's output signal and it can be presented as

Where

$$
\mathrm{V}_{\mathrm{i}}=\mathrm{C}_{1} \mathrm{H}_{\mathrm{i}} \varepsilon\left(\lambda_{\mathrm{i}}, \mathrm{T}\right) \lambda_{\mathrm{i}}^{-5}\left(\exp \frac{\mathrm{C}_{2}}{\lambda_{\mathrm{i}} \mathrm{T}}-1\right)^{-1} \quad \mathrm{i}=1,2,3, \ldots \ldots, 8
$$

$\lambda_{\mathrm{i}}$ is the ith light beam's wavelength $(\mu \mathrm{m})$,

$\mathrm{T}$ is black body's absolute temperature $(\mathrm{K})$,

$\varepsilon\left(\lambda_{\mathrm{i}}, \mathrm{T}\right)$ is spectral emissivity,

$\mathrm{H}_{\mathrm{i}}$ is a geometrical factor

$\mathrm{H}_{\mathrm{i}}$ related to spectral response rate of the detector and optical components transmissivity, needs to be determined by calibration. To simplify calculation, we use Wien formula instead of Planck formula, and get formula (3).

$$
\mathrm{V}_{\mathrm{i}}=\mathrm{C}_{1} \mathrm{H}_{\mathrm{i}} \varepsilon\left(\lambda_{\mathrm{i}}, \mathrm{T}\right) \lambda_{\mathrm{i}}^{-5} \exp \left(-\frac{\mathrm{C}_{2}}{\lambda_{\mathrm{i}} \mathrm{T}}\right){ }_{i=1,2,3, \ldots \ldots, 8}
$$

According to this formula, we can get eight equations for every aimed point in a flame, which includes true temperature $\mathrm{T}$ and spectral emissivity. ${ }^{\varepsilon}\left(\lambda_{\mathrm{i}}, \mathrm{T}\right)$ has 9 unknown numbers.

In the field of the multispectral radiation temperature measurement, it is generally believed that spectral emissivity changes over the wavelength. So, to facilitate the automatic optimization process, we can use the following function to express the relationship between wavelength and emission rate:

According to (3):

$$
\ln \varepsilon\left(\lambda_{i}, T\right)=\sum_{j=0}^{m} a_{j} \lambda_{i}^{j} i_{i=1,2,3, \ldots . ., m} \quad m \leq 6
$$

$$
\ln \frac{V_{i} \lambda_{i}^{5}}{C_{1} H_{i}}=-\frac{C_{2}}{\lambda_{\mathrm{i}} T}+\ln \varepsilon\left(\lambda_{i}, T\right)
$$

Put (4) into (5): 


$$
\ln \frac{V_{i} \lambda_{i}^{5}}{C_{1} H_{i}}=-\frac{C_{2}}{\lambda_{\mathrm{i}} T}+\mathrm{a}_{0}+\mathrm{a}_{1} \lambda_{i}+a_{2} \lambda_{i}^{2}+\cdots+\mathrm{a}_{6} \lambda_{i}^{6}
$$

After rearranging:

$$
\mathrm{y}_{\mathrm{i}}=\ln \frac{V_{i} \lambda_{i}^{5}}{C_{1} H_{i}}, \mathrm{x}_{1, \mathrm{i}}=\lambda_{i}, \mathrm{x}_{2, \mathrm{i}}=\lambda_{i}^{2}, \cdots \cdots, \mathrm{x}_{6, \mathrm{i}}=\lambda_{i}^{6}, \mathrm{x}_{7, \mathrm{i}}=\frac{1}{\lambda_{i}}, \mathrm{a}_{7}=-\frac{C_{2}}{\lambda_{\mathrm{i}} T}, \quad \mathrm{i}=1,2,3, \ldots \ldots, 8 \quad \mathrm{~m}=6
$$

Denote this as a nonlinear equation $\mathrm{y}_{\mathrm{i}}=\mathrm{a}_{0}+\mathrm{a}_{1} \mathrm{x}_{1}+a_{2} \mathrm{x}_{2}+\cdots+\mathrm{a}_{7} \mathrm{x}_{7}$, then we can use least square method to solve the equation and get the parameters: $a_{0}, a_{1}, \ldots . ., a_{7}$. According to ${ }^{a_{7}=-\frac{C_{2}}{\lambda_{i} T}}$ and (4), T and $\varepsilon\left(\lambda_{i}, T\right)$ can be calculated. However, it is only feasible in theory, because the equations are nonlinear and difficult to solve, and to get $a_{0}, a_{1}, \ldots . . ., a_{7}$ is nearly impossible on actual calculation.

\subsection{Flame Vertical Temperature Field Inversion}

This section of the proposed algorithm will be an extension of the basic methods of temperature measurement introduced in 3.2, and solve the problems occurred in the above algorithm. Take a flame longitudinal section $M$ as an example in Figure 2. The section is divided into 8 parts, $A_{1} 、 A_{2} 、 \ldots \ldots, A_{8}$, and the temperature of ith is $T_{i}, \quad 1 \leq i \leq 8$. After going through color filter and acquisition board, we can get eight $\mathrm{E}_{\mathrm{i}}$ for different radiation intensity.

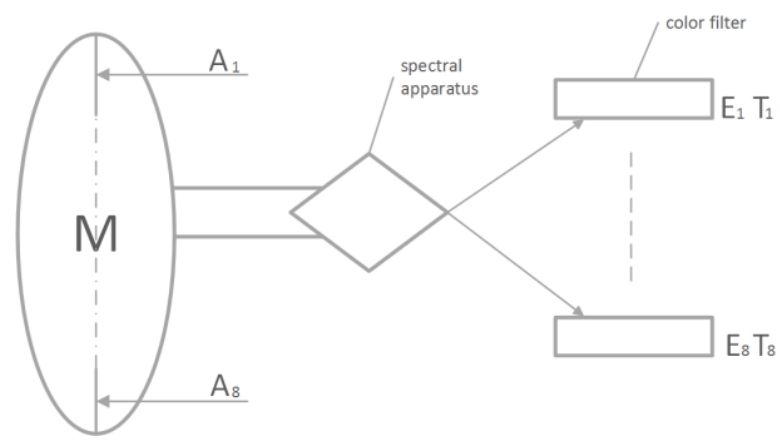

Figure 2. Flame Longitudinal Section

Using the method proposed in 3.2, temperature $\mathrm{T}$ (under the effect of $\mathrm{T}_{1}, \mathrm{~T}_{2}$,

$\mathrm{T}_{8}$ ) of the part $\mathrm{M}$ can be measured. The radiation intensity of $\mathrm{M}$ is the result of interaction of eight regional radiations. In this situation, we simply assume that it is the sum of eight regional radiations. The value of radiation with the filter can be calculated by the formula (7).

$$
\mathrm{E}(\lambda, \mathrm{T})=\mathrm{E}\left(\lambda, \mathrm{T}_{1}\right)+\mathrm{E}\left(\lambda, \mathrm{T}_{2}\right)+\cdots+\mathrm{E}\left(\lambda, \mathrm{T}_{8}\right)
$$

According to (6) and eight different wavelength, there are eight equations, as shown in (7), the unknown number is $\mathrm{T}_{1}, \mathrm{~T}_{2}, \ldots \ldots, \mathrm{T}_{8}$.

$$
\left\{\begin{array}{r}
\mathrm{E}\left(\lambda_{1}, \mathrm{~T}\right)=\mathrm{E}\left(\lambda_{1}, \mathrm{~T}_{1}\right)+\mathrm{E}\left(\lambda_{1}, \mathrm{~T}_{2}\right)+\cdots+\mathrm{E}\left(\lambda_{1}, \mathrm{~T}_{8}\right) \\
\mathrm{E}\left(\lambda_{2}, \mathrm{~T}\right)=\mathrm{E}\left(\lambda_{2}, \mathrm{~T}_{1}\right)+\mathrm{E}\left(\lambda_{2}, \mathrm{~T}_{2}\right)+\cdots+\mathrm{E}\left(\lambda_{2}, \mathrm{~T}_{8}\right) \\
\cdots \cdots \\
\mathrm{E}\left(\lambda_{8}, \mathrm{~T}\right)=\mathrm{E}\left(\lambda_{8}, \mathrm{~T}_{1}\right)+\mathrm{E}\left(\lambda_{8}, \mathrm{~T}_{2}\right)+\cdots+\mathrm{E}\left(\lambda_{8}, \mathrm{~T}_{8}\right)
\end{array}\right.
$$

Assuming that the temperature of $A_{1}, A_{2}, \ldots \ldots, A_{8}$ is $T_{1}, T_{2}, \ldots \ldots, T_{8}$ at first, bring these into (7), calculate $E^{\prime}\left(\lambda_{1}, T\right), E^{\prime}\left(\lambda_{2}, T\right), \ldots \ldots, E^{\prime}\left(\lambda_{8}, T\right)$. Compare with the actual collected radiation value $\mathrm{E}\left(\lambda_{1}, \mathrm{~T}\right), \mathrm{E}\left(\lambda_{2}, \mathrm{~T}\right), \ldots \ldots, \mathrm{E}\left(\lambda_{8}, \mathrm{~T}\right)$. The error between them is $\mathrm{d}$.

$$
d=\left|E^{\prime}\left(\lambda_{1}, T\right)-E\left(\lambda_{1}, T\right)\right|+\left|E^{\prime}\left(\lambda_{2}, T\right)-E\left(\lambda_{2}, T\right)\right|+\cdots+\left|E^{\prime}\left(\lambda_{8}, T\right)-E\left(\lambda_{8}, T\right)\right|
$$


Here, use PSO to get the optimal solution of these equations. Particles update themselves by tracking two "extreme value" in iterations. The first one is personal best, pBest, and the second one is global best, gBest. When finding these two points, particle will update its speed and position according to the following formula (10) and (11).

$$
\begin{gathered}
\mathrm{v}=\mathrm{v}+\mathrm{c}_{1} * \text { rand } *(\text { pbest }- \text { present })+\mathrm{c}_{2} * \operatorname{rand}() *(\text { gbest }- \text { present }) \\
\text { present }=\text { present }+\mathrm{v}
\end{gathered}
$$

In the formula, $\mathrm{v}$ is particle's speed, present is current position, rand is a random number between 0 and $1, \mathrm{c}_{1}$ and $\mathrm{c}_{2}$ is learning factor, normally, $\mathrm{c}_{1}=\mathrm{c}_{2}=2$.

According to PSO, the solution $\mathrm{t}_{1}, \mathrm{t}_{2}, \ldots \ldots, \mathrm{t}_{8}$ of $\mathrm{T}_{1}, \mathrm{~T}_{2}, \ldots \ldots, \mathrm{T}_{8}$ can be seen as particle in searching space, and error $d$ is the fitness value of particle. Every particle has a speed, which determines its direction and distance. $t_{1}, t_{2}, \ldots . ., t_{8}$ are initialized as a group of random particles, and then adjust their own speed dynamically according to comprehensive analysis. Searching in the solution space, finally find the optimal solution by iteration. pBest is personal extreme and gBest is global extreme. Every particle updates its speed and position according to this two extreme value in each iteration process. $v_{i j}^{k}$ is the ith particle's speed in the kth iteration. $x_{i j}^{k}$ is the ith particle's position in the kth iteration. The update formula is (12) and (13).

$$
\begin{gathered}
\mathrm{v}_{i}^{k+1}=v_{i}^{k}+c_{1} r_{1}\left(\text { pbest }_{i}^{k}-x_{i}^{k}\right)+c_{2} r_{2}\left(\text { gbest }_{i}^{k}-x_{i}^{k}\right) \\
x_{i}^{k+1}=x_{i}^{k}+v_{i}^{k}
\end{gathered}
$$

When the error $d$ is less than or equals to the threshold $\sigma$, illustrating the radiation value error is in an acceptable range at this point. So the solution $t_{1}, t_{2}, \ldots \ldots, t_{8}$ can be seen as sectional temperature $T_{1}, T_{2}, \ldots \ldots, T_{8}$ the Vertical flame temperature field distribution. The algorithm is indicated below:

Algorithm: flame vertical temperature field inversion based on spectral radiant

Input: particle number: $n=20$, solution space dimension: $\operatorname{dim}=8$

Output: the best solution for temperature: $\mathrm{t}[8]$

Terminal condition: find the best solution or the iterations reach 100

Variable declaration:

$\mathrm{t}[\mathrm{dim}]:$ particle's position, solution for temperature

$\mathrm{v}[\mathrm{dim}]$ : particle's speed

fitness[dim]: error

pBest_fitness[dim]: particle's best personal extreme

pBest[dim]: particle's position when gets pBest

gBest: the particle with best fitness.

Step1: Initialize every particle, and particle number is 20.

Step1.1: Randomly initialize every particle's position t[i] and speed v[i] in solution space's each dimension. Every particle's position and speed in dimension $\mathrm{i}$ is determined by formula (12) and (13). $i=1,2, \ldots \ldots, 8$

Step1.2: calculate every particle's fitness in dimension i according to fitness function, and search for personal extreme to initiate pBest_fitness

Step1.3: init gBest with the particle's number that has best fitness.

Step1.4: initpBest[i] with t[i]

Step2: Loop iteration, judging if meets the termination conditions. If the answer is yes, jump to Step3, else jump to Step2.1

Step2.1: calculate every particle's fitness: fitness [i].

Step2.2: if finess[i]<pBest_fitness[i], modify the value of pBest_finess[i] and pBest[i], make $\mathrm{pBest} \_$fitness[i]=finess[i], and pBest[i]=x[i]

Step2.3: search for gBest, if pBest_fitness[i]<pBest_fitness[gBest], then change gBest's value, give the particle's number to gBest, gBest $=\mathrm{I}$.

Step2.4: every particle updates t[i] and v[i] according to (12) and (13). Jump to step2. 
Step3: end the program and output the best solution $\mathrm{t}[8]$ for temperature.

\section{Experiment and Results}

\subsection{Method}

To validate the performance of presented flame longitudinal temperature field inversion algorithm based on multi-spectral radiation, the following experiment had been performed on the eight-wavelength data acquisition system mentioned before.

The experiment steps are as follows:

1. Arrange experiment system and laboratory equipment

For Horizontal optical platform, adjust the speculum group until the system obtains the largest light signal strength. The flame light passes through the spectroscopic device, and through eight different wavelengths of color filter respectively. Color Filters position should be adjusted on the same level. Photosensitive diode converts eight different wavelengths of light signal into voltage signal. And the computer can get the data from the acquisition board. The wavelength of 8 -channel filter shows in Table 1.

Table 1. Wavelength of 8-Channel Filter

\begin{tabular}{|l|l|l|l|l|l|l|l|l|}
\hline Channel & 1 & 2 & 3 & 4 & 5 & 6 & 7 & 8 \\
\hline Wavelength $(\mathrm{nm})$ & 621 & 632.8 & 650 & 659.5 & 670 & 680 & 702 & 710 \\
\hline
\end{tabular}

\section{Calibration}

Since the photodiode will convert light signal into voltage signal, the computer only can obtain voltage signal from data acquisition board. But radiation intensity signal is needed in order to measure the temperature. Because of the correlation between optical radiation intensity and voltage, the functional relationship can be fitted by blackbody furnace calibration. The calibration data are shown in Table 2, and eight different wavelengths and temperatures corresponding to the radiation intensity are shown in Table 3. Optical radiation intensity and voltage relationship fitting results are shown in Figure 3.

Table 2. Relationship between Temperature and Voltage

\begin{tabular}{|c|l|l|l|l|l|l|l|l|}
\hline $\begin{array}{c}\text { Channel } \\
\text { Temperature }\end{array}$ & 1 & 2 & 3 & 4 & 5 & 6 & 7 & 8 \\
\hline 892 & 2.42 & 2.10 & 1.72 & 1.57 & 1.43 & 1.31 & 1.10 & 1.06 \\
\hline 1000 & 3.11 & 2.62 & 2.13 & 1.91 & 1.72 & 1.55 & 1.29 & 1.21 \\
\hline 1098 & 3.89 & 4.24 & 2.79 & 2.55 & 2.02 & 1.82 & 1.67 & 1.55 \\
\hline 1298 & 6.17 & 5.01 & 3.79 & 3.32 & 3.10 & 2.52 & 1.96 & 1.96 \\
\hline 1399 & 8.82 & 6.17 & 4.57 & 3.94 & 3.52 & 2.95 & 2.27 & 2.07 \\
\hline 1508 & 9.89 & 7.82 & 5.63 & 4.81 & 4.05 & 3.50 & 2.62 & 2.39 \\
\hline
\end{tabular}

Table 3. Relationship between Temperature and Radiation Intensity

\begin{tabular}{|c|l|l|l|l|l|l|l|l|}
\hline $\begin{array}{c}\text { Wavelength } \\
\text { Temperature }\end{array}$ & 621 & 632.8 & 650 & 659.5 & 670 & 680 & 702 & 710 \\
\hline 892 & 1.54 & 1.43 & 1.28 & 1.21 & 1.14 & 1.07 & 0.94 & 0.91 \\
\hline 1000 & 1.73 & 1.60 & 1.44 & 1.36 & 1.28 & 1.20 & 1.06 & 1.01 \\
\hline 1098 & 1.90 & 1.76 & 1.58 & 1.49 & 1.40 & 1.32 & 1.17 & 1.11 \\
\hline 1298 & 2.25 & 2.09 & 1.88 & 1.78 & 1.66 & 1.57 & 1.38 & 1.32 \\
\hline 1399 & 2.43 & 2.25 & 2.02 & 1.91 & 1.79 & 1.69 & 1.49 & 1.42 \\
\hline 1508 & 2.62 & 2.43 & 2.18 & 2.06 & 1.93 & 1.82 & 1.60 & 1.53 \\
\hline
\end{tabular}




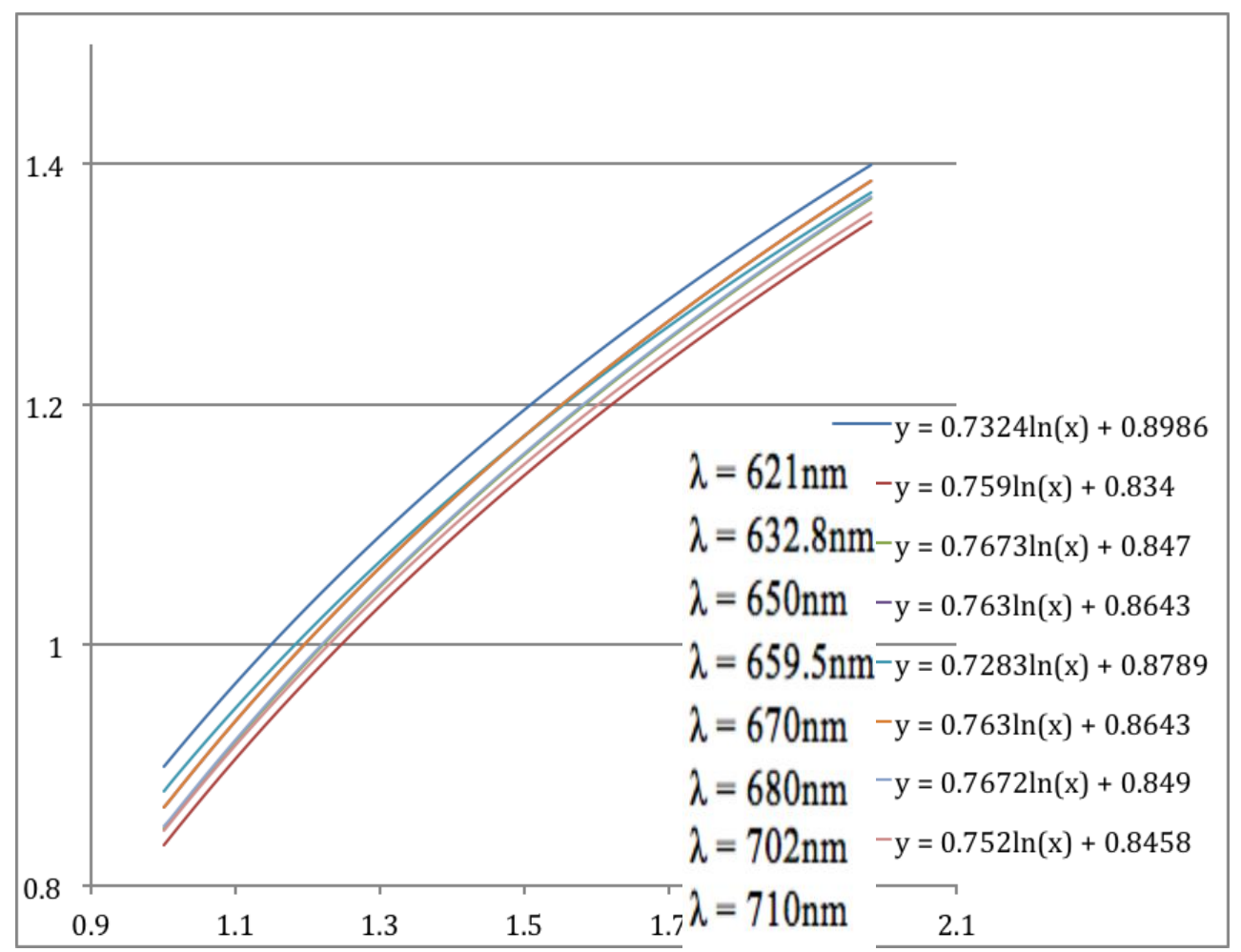

Figure 3. Voltage and Radiation Intensity's Fitting Result

3. Vertical temperature field inversion

In the flame vertical temperature field inversion experiment, we measured the temperature of flame in different time point, respectively, and calculated the inversion result. Flame from an industrial furnace of one Chinese power plant was tested. Figure 4 shows four-flame image at different time point. Black part in the picture is pulverized coal being injected into the furnace.

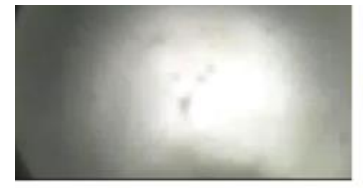

(1) $\mathrm{t}=10 \mathrm{~min}$

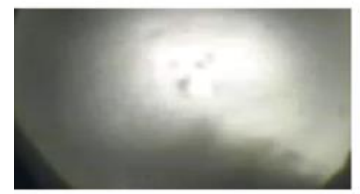

(3) $\mathrm{t}=30 \mathrm{~min}$

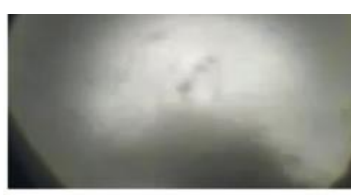

(2) $t=20 \min$

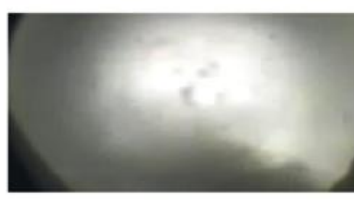

(4) $\mathrm{t}=40 \mathrm{~min}$

Figure 4. Furnace Flame

The experimental results using particle swarm optimization algorithm for fast convergence. Set the algorithm's iteration time as 500 , particle number $\mathrm{n}$ as 20 , dimension of solution space dim as 8 , learning factor $\mathrm{c} 1=\mathrm{c} 2=2$, then on the basis of algorithm described in 2.3 to calculate and get the final result. The inversion results of time point 1 to 4 are shown in Table 4 to 7 . Each time of inversion is denoted by a serial number. 
Table 4. Flame Vertical Temperature Inversion Results $\left({ }^{\circ} \mathrm{C}\right)$ for Time Point 1

\begin{tabular}{|l|c|c|c|c|c|c|c|c|}
\hline $\begin{array}{l}\text { vertical } \\
\text { position } \\
\text { number }\end{array}$ & 1 & 2 & 3 & 4 & 5 & 6 & 7 & 8 \\
\hline 1 & & & & & & & & \\
\hline 2 & 1270.84 & 1392.68 & 1421.39 & 1561.99 & 1505.07 & 1402.17 & 1340.65 & 1217.80 \\
\hline 3 & 1225.05 & 1376.70 & 1482.16 & 1525.30 & 1546.59 & 1473.92 & 1316.44 & 1256.82 \\
\hline 4 & 1278.08 & 1390.21 & 1456.91 & 1551.12 & 1579.03 & 1474.58 & 1358.36 & 1231.03 \\
\hline 5 & 1238.62 & 1383.11 & 1462.76 & 1551.57 & 1543.74 & 1464.53 & 1350.68 & 1283.39 \\
\hline 6 & 1229.47 & 1396.07 & 1465.51 & 1516.26 & 1589.04 & 1479.96 & 1310.02 & 1210.65 \\
\hline 7 & 1286.36 & 1304.60 & 1483.38 & 1537.51 & 1537.77 & 1396.62 & 1305.23 & 1257.28 \\
\hline 8 & 1240.42 & 1364.57 & 1449.55 & 1563.27 & 1504.57 & 1471.33 & 1335.02 & 1199.74 \\
\hline
\end{tabular}

Table 5. Flame Vertical Temperature Inversion Results $\left({ }^{\circ} \mathrm{C}\right)$ for Time Point 2

\begin{tabular}{|l|l|l|l|l|l|l|l|l|}
\hline $\begin{array}{l}\text { vertical } \\
\text { position } \\
\text { number }\end{array}$ & 1 & 2 & 3 & 4 & 5 & 6 & 7 & 8 \\
\hline 1 & & & & & & & & \\
\hline 2 & 1209.45 & 1300.43 & 1454.58 & 1587.35 & 1547.41 & 1447.34 & 1392.07 & 1251.09 \\
\hline 3 & 1292.51 & 1392.61 & 1396.70 & 1534.99 & 1553.09 & 1473.28 & 1324.52 & 1286.63 \\
\hline 4 & 1275.49 & 1397.10 & 1427.87 & 1583.23 & 1580.35 & 1442.50 & 1376.90 & 1284.10 \\
\hline 5 & 1276.60 & 1389.24 & 1408.26 & 1546.38 & 1526.08 & 1432.91 & 1338.98 & 1284.54 \\
\hline 6 & 1250.25 & 1348.67 & 1489.70 & 1580.74 & 1563.49 & 1427.52 & 1391.75 & 1223.14 \\
\hline 7 & 1211.54 & 1372.58 & 1420.77 & 1520.61 & 1554.21 & 1488.27 & 1335.41 & 1221.41 \\
\hline 8 & 1283.45 & 1342.07 & 1466.23 & 1559.42 & 1522.09 & 1463.49 & 1359.28 & 1282.65 \\
\hline
\end{tabular}


Table 6. Flame Vertical Temperature Inversion Results $\left({ }^{\circ} \mathrm{C}\right)$ for Time Point 3

\begin{tabular}{|l|c|c|c|c|c|c|c|c|}
\hline $\begin{array}{l}\text { vertical } \\
\text { position }\end{array}$ & & & & & & & & \\
number & 1 & 2 & 3 & 4 & 5 & 6 & 7 & 8 \\
\hline 1 & & & & & & & & \\
\hline 2 & 1293.75 & 1395.07 & 1478.08 & 1532.47 & 1523.67 & 1441.10 & 1368.47 & 1296.37 \\
\hline 3 & 1243.29 & 1391.02 & 1466.40 & 1529.10 & 1589.64 & 1402.47 & 1386.93 & 1283.94 \\
\hline 4 & 1282.37 & 1335.26 & 1458.33 & 1530.68 & 1585.92 & 1393.83 & 1356.32 & 1204.34 \\
\hline 5 & 1262.37 & 1385.46 & 1474.44 & 1493.07 & 1515.02 & 1464.26 & 1383.94 & 1225.23 \\
\hline 6 & 1289.26 & 1324.94 & 1463.18 & 1504.35 & 1568.92 & 1451.14 & 1394.14 & 1215.90 \\
\hline 7 & 1227.86 & 1372.58 & 1408.69 & 1554.84 & 1582.99 & 1481.39 & 1354.55 & 1247.89 \\
\hline 8 & 1221.26 & 1344.31 & 1447.34 & 1574.10 & 1526.91 & 1465.12 & 1378.53 & 1213.88 \\
\hline
\end{tabular}

Table 7. Flame Vertical Temperature Inversion Results $\left({ }^{\circ} \mathrm{C}\right)$ for Time Point 4

\begin{tabular}{|l|c|c|c|c|c|c|c|c|}
\hline $\begin{array}{c}\text { vertical } \\
\text { position } \\
\text { number }\end{array}$ & 1 & 2 & 3 & 4 & 5 & 6 & 7 & 8 \\
\hline 1 & & & & & & & & \\
\hline 2 & 1265.39 & 1336.27 & 1394.33 & 1548.97 & 1527.52 & 1438.71 & 1349.97 & 1199.87 \\
\hline 3 & 1240.56 & 1369.49 & 1393.46 & 1563.68 & 1521.53 & 1446.31 & 1360.81 & 1247.49 \\
\hline 4 & 1222.18 & 1366.01 & 1468.16 & 1502.98 & 1588.92 & 1464.15 & 1393.43 & 1233.46 \\
\hline 5 & 1239.45 & 1357.22 & 1443.56 & 1517.74 & 1499.33 & 1395.03 & 1329.61 & 1258.53 \\
\hline 6 & 1222.26 & 1335.81 & 1426.64 & 1537.20 & 1559.15 & 1445.24 & 1392.89 & 1244.14 \\
\hline 7 & 1211.63 & 1330.48 & 1410.31 & 1581.65 & 1534.58 & 1401.22 & 1331.72 & 1282.42 \\
\hline 8 & 1279.74 & 1319.84 & 1411.37 & 1528.57 & 1573.74 & 1465.71 & 1304.33 & 1266.28 \\
\hline
\end{tabular}

Compare the calculated value with the temperature value measured by thermocouple of type $\mathrm{B}$, and then calculate the absolute error $(\mathrm{E}=\mathrm{x}-\mathrm{xT}, \mathrm{x}$ is measurement value, and $\mathrm{xT}$ is true value) and relative error $\left(\delta=\Delta / L^{*} 100 \%, \delta\right.$ is relative error, $\Delta$ is absolute value, and $\mathrm{L}$ is true value). The result is shown in Table 8. The error analysis shows that the proposed temperature measurement method is feasible, and the error is small enough to accept, and calculation time is short.

Table 5. Error Analysis

\begin{tabular}{|l|l|l|l|}
\hline Time point & Absolute error $\left({ }^{\circ} \mathrm{C}\right)$ & Relative error $(\%)$ & Calculation time(s) \\
\hline $\mathrm{t} 1$ & 28.51 & 2.04 & 2.37 \\
\hline $\mathrm{t} 2$ & 18.42 & 1.34 & 2.94 \\
\hline $\mathrm{t} 3$ & 25.41 & 1.82 & 3.29 \\
\hline $\mathrm{t} 4$ & 35.57 & 2.33 & 2.11 \\
\hline
\end{tabular}




\subsection{Comparison}

The current mainstream method for temperature measurement is contact and noncontact method. Among the contact methods, the most widely used is the thermocouple measurement and thermal resistor temperature measurement method. This method is easy to operate, and can obtain true temperature. However, it cannot be applied to the long time or high temperature occasion, and due to its poor dynamic character it must contact with the object to be tested. This method can only measure the real temperature of a single point in the flame. If we want to reconstruct the temperature field, a large amount of thermocouples should be distributed into every point of the flame. Although it is feasible theoretically, it cannot be applied to the real engineering.

For non-contact measurement method, single wavelength optical pyrometer and colorimetric thermometer is frequently used. However, it cannot get real temperature of the object, but only acquires approximate temperature through brightness, color and other characteristics, and knows material emissivity to get the real temperature of the object. And the material emissivity is related to the composition of the object, object's surface status and the temperature. It's also easy to change with the surface status, so it is very difficult to measure. Thus, the existing non-contact temperature measurement method has low accuracy and the temperature field inversion result always has bigger error.

The multispectral radiation thermometry introduced and used here also belongs to the non-contact temperature measuring method. It has all the advantages of non-contact measurement method, including large temperature measurement range, temperature measurement process not affecting the original temperature field distribution, short response time, obtaining the material emissivity of the object through the data processing of multiple spectral radiation information, and making up for defects of past single wavelength optical pyrometer. Flame temperature field can be reconstructed by the vertical flame section temperature field inversion algorithm, which is proposed in this manuscript. And after experimental verification, the error range of measuring results is relatively smaller (below 2.5\%). Compared with previous industrial flame temperature measurement method, it is a great breakthrough.

\section{Conclusion}

Our study showed a new flame temperature measurement method based on the principle of the multispectral radiation. Experiment verified that this method has following advantages: non-contact, wide temperature range, fast measuring speed, the acceptable longitudinal temperature field, and less error. Furthermore, this method also reconstructs the vertical flame section temperature field, which is helpful to understand the combustion condition of industrial boilers. It is clearly superior to the previous contact temperature measurement method and provides a new way for monitoring combustion condition of large coal-fired boiler, has great significance to ensure the safety of boiler, improve the economic benefit, and promote energy conservation and environmental protection.

\section{References}

[1] H. A. Abdel-Aal, "Contact Temperature Measuremen", Springer US, (2013).

[2] P. A. Kinzie and L. G. Rubin, "Thermocouple Temperature Measurement", Physics Today, vol 26, no. 11, (1973), pp. 52-55.

[3] M. V. Heitor and A. L. N. Moreira, "Thermocouples and sample probes for combustion studies", Progress in Energy and Combustion Science, vol. 19, no. 3, (1993), pp. 259-278.

[4] M. A. Khan, C. Allemand and T. W. Eagar, "Noncontact temperature measurement. I. Interpolation based techniques", Review of Scientific Instruments, vol. 62, no. 2, pp. 392-402.

[5] N. Docquire and S. Candel, "Combustion control and sensors: a review", Prog. Energy and Combustion Sci., vol. 28, (2002), pp. 107-150. 
[6] H. Zhou, X. Lou, J. Xiao, Y. Heling, D. Yuankai, G. Yizhi, X. Fangling and S. Guojun, "Experimental Study on Image Processing of Flame Temperature Distribution in a Pilot-scale Furnace", Zhongguo Dianji Gongcheng Xuebao/proceedings of the Chinese Society of Electrical Engineering, vol. 15, no. 5, (1995), pp. 295-300.

[7] L. Dong, J. Yan, W. Fei, Q. Huanga, Y. Chia and K. Cena, "Experimental reconstructions of flame temperature distributions in laboratory-scale and large-scale pulverized-coal fired furnaces by inverse radiation analysis", Fuel, vol. 93, no. 1, (2011), pp. 397-403.

[8] D. Liu, Q. Huanga, Y. Chia and K. Cena, "Experimental reconstructions of flame temperature distributions in laboratory-scale and large-scale pulverized-coal fired furnaces by inverse radiation analysis", Fuel, vol. 93, no. 41-42, (2012), pp. 397-403.

[9] M. A. Khan, C. Allemand and T. W. Eagar, "Noncontact temperature measurement. II. Least squares based techniques", Review of Scientific Instruments, vol. 62, no. 2, (1991), pp. 403-409.

[10] Y. U. Y. feng, T. C. Zhao and X. U. W. Yong, "Analyzing the Judgment of Flame in Pulverized Coal Combustion”, Journal of Shanghai Jiaotong University, (2000).

[11] I. Ihara and M. Takahashi, "Non-invasive monitoring of temperature distribution inside materials with ultrasound inversion method", International Journal of Intelligent Systems Technologies \& Applications, vol. 7, no. 1, (2009), pp. 80-91.

[12] C. Lou and H. C. Zhou, "Deduction of the two-dimensional distribution of temperature in a cross section of a boiler furnace from images of flame radiation", Combustion \& Flame, vol. 143, no. 1-2, (2005), pp. 97-105.

[13] C. Cheng and K. Zhang, "Research on temperature field and temperature stress of prestressed concrete girders", International Journal of Intelligent Systems \& Applications, vol. 3, no. 1, (2011).

[14] E. C. Pyatt, "Some consideration of the errors of brightness and two-colour types of spectral radiation pyrometer", British Journal of Applied Physics, vol. 5, no. 5, (1954), pp. 264-268.

[15] P. M. Reynolds, "A review of multicolour pyrometry for temperatures below $1500^{\circ}$ C", British Journal of Applied Physics, vol. 15, no. 5, (1964), pp. 579-589.

[16] D. I. Svet, "Determination of the emissivity of a substance from the spectrum of its thermal radiation and optimal methods of optical pyrometry", High Temperatures-High Pressures, vol. 8, no. 5, (1976), pp. 493-498.

[17] G. A. Lyzenga and T. J. Ahrens, "Multiwavelength optical pyrometer for shock compression experiments", Review of Scientific Instruments, vol. 50, no. 11, (1979), pp. 1421-1424.

[18] M. A. Khan, C. Allemand and T. W. Eagar, "Emissivity independent multiwavelength pyrometer".

\section{Authors}

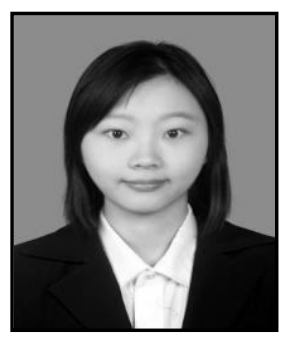

Binyang Li, 1991.09, Female. Master's degree. Flame temperature field reconstruction. 
International Journal of Multimedia and Ubiquitous Engineering

Vol.12, No.2 (2017) 